\title{
Além da Oftalmologia
}

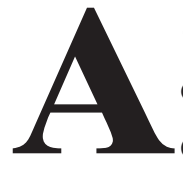

Coordenação de Aperfeiçoamento de Pessoal para o Ensino Superior (CAPES), órgão do Ministério da Educação e Cultura, classifica as publicações científicas perió dicas brasileiras de acordo com sua qualidade. Os diferentes níveis de classificação são: A1, A2, B1,B2,B3,B4,B5 e C. O nível A1 é o maior e o nível C,o menor.

A CAPES também avalia e classifica os cursos de pós-graduação "strictosensu" em nosso país. Um dos elementos mais importantes desta avaliação é a produção bibliográfica do corpo permanente de docentes. Um curso cuja produção bibliográfica seja pequena ou ruim pode ser descredenciado de continuar funcionando.A avaliação desta produção para o curso é baseada atualmente na quantidade de artigos publicados por docente em um período de três anos e no nível de qualidade ou na classificação do periódico científico no qual os artigos foram publicados. Avaliações cujo resultados indiquem produção intelectual de nível alto favorecem a obtenção de recursos por parte de organizações de fomento à pesquisa seja para o curso ou para o pesquisador.

A Revista Brasileira de Oftalmologia (RBO) é classificada de forma diferenciada de acordo com critérios específicos referentes às diversas áreas da ciência para as quais ela contribui. A RBO é classificada pela CAPES nas seguintes áreas:

a) B2 em Saúde Coletiva, Engenharias III e Interdisciplinar;

b) B3 em Medicina Clínica II;

c) B4 em Medicina Clínica I e III;

d) B4 em Biotecnologia.

A natureza das informações veiculadas na RBO não é exclusiva da área médica, embora sejam publicadas predominantemente por oftalmologistas. Há inúmeros artigos nos quais tecnologias complexas de diagnóstico e tratamentos são avaliados clínica ou cirurgicamente, o que pode interessar às áreas de engenharia e biotecnologia. Muitos trabalhos estudam prevalência de doenças oculares em populações de diversas regiões do Brasil, o que é útil para o planejamento de políticas públicas de saúde e consequentemente à área de Saúde Coletiva. Artigos publicados em que os resultados dependeram do trabalho coordenado de profissionais de áreas diferentes do saber, que interagiram durante o processo, são exemplos de produções interdisciplinares.

A RBO fornece informações úteis para certas áreas de Medicina Clínica (Medicina I), Cirúrgica (Medicina III) ou de Pediatria entre outras (Medicina II), devido à ampla relação da oftalmologia com as doenças sistêmicas e a medicina em geral. Tal contribuição fica clara quando observamos que nas estatísticas da base de dados SciElo, o artigo mais acessado pela revista até a data em que escrevo este editorial foi um relato de caso da Síndrome de Von Wildervanck (Síndrome óculo-cervico-acústica) publicada em 2008 e que apresentou 7784 acessos desde 
quando a RBO foi indexada nesta base há cerca de 3 anos. O número de acessos foi 1436 vezes maior do que o segundo artigo mais acessado. Este relato de caso desperta interesse de especialidades médicas distintas como: oftalmologia, pediatria, otorrinolaringologia e neurologia, entre outras. Dos 80 artigos mais acessados da RBO no SciElo, cerca de 30\% se referem a alterações oftálmicas de doenças sistêmicas.

O fato do artigo mais acessado da RBO desde sua indexação no Scielo ser um relato de caso de uma síndrome rara e de grande parte dos artigos mais lidos pela internet associarem a oftalmologia a outras especialidades médicas parece indicar que, além do interesse oftalmológico e acadêmico, há também um interesse médico geral e multidisciplinar importante entre os leitores da revista. Consequentemente, tanto a CAPES quanto as estatísticas de acesso à RBO no SciElo apontam que a contribuição da RBO à ciência brasileira vai além da oftalmologia.

Arlindo José Freire Portes Professor Adjunto de Oftalmologia da Universidade Estácio de Sá-RJ. Editor-Chefe da Revista Brasileira de Oftalmologia de 2011 a 2012 